[Technical Paper]

\title{
High Thermal Conductivity AlN Fillers Using Carbo-thermal- reduction and Nitridation Process
}

\author{
Akimasa Kuramoto, Yutaka Fukunaga, Yasushi Imoto, Yoshitaka Inaki, Saiko Fujii, Meng Wang, \\ Yukihiro Kanechika, Teruhiko Nawata, and Masahide Ueda
}

Specialty Products Development Dept., Tokuyama Corporation, Shunan, Yamaguchi 745-8648, Japan

(Received August 9, 2018; accepted June 5, 2019, published August 19, 2019)

\begin{abstract}
Novel aluminum nitride (AlN) fillers with large particle size and round shape were developed using the carbo-thermal reduction and nitridation (CRN) method in this study. They were used as high thermal conductivity fillers for resin composites. Thermal conductivity of epoxy resin filled with the AlN filler could reach $12 \mathrm{~W} / \mathrm{m} \mathrm{K}$. The fluidity of the epoxy resin filled with the developed AlN filler was improved to 1.3 times that of conventional resin. Also, viscosity of silicon resin filled with the AlN filler was one tenth lower than the conventional AlN filler. The properties and evaluation of the developed AlN filler for high thermal conductivity packaging material have also been discussed.
\end{abstract}

Keywords: Aluminum Nitride, Thermal Conductivity, Filler, Resin Material, Carbo-thermal-reduction Method

\section{Introduction}

Aluminum nitride (AlN) has excellent properties, such as high thermal conductivity, high insulation resistivity, high corrosion resistance and low thermal expansion coefficient similar to that of silicon. Therefore, AlN ceramic has been used as heat sink and packaging materials for high power devices. [1, 2]

The high packaging density and downsizing of electronic devices have several problems that are related to the increase in heat density. Thus, the development of high thermal conductivity material for packaging is constantly expected.

AlN powder is suitable for high thermal conductivity filler for resin composites, such as thermal interface material and metal-based substrate. Controlling the particle size and morphology of the AlN filler is crucial to achieve high thermal conductivity. Large and spherical morphology are desirable to filler in their applications. In previous studies, there are many researches on AlN filler for resin.[3-9] Highly close-packed structure is obtained by filling small particles among large particles. The greater the number of contact points among the filler particles, the greater the thermal conductivity. The spherical morphology has better filling properties.

However, no appropriate AlN fillers with large and spherical morphologies are available so far. Large AlN fill- ers can be obtained using a direct nitridation method. The overall reaction that takes place during this method is as follows.

$$
2 \mathrm{Al}+\mathrm{N}_{2} \rightarrow 2 \mathrm{AlN}
$$

Direct nitridation process is a self-generated heat reaction. Therefore, controlling the reaction is very difficult. The process involves hard agglomeration after the reaction, and their pulverization is necessary. Thus, developing a sphere shaped filler is difficult.

Granule-sintered-type AlN is used as a large spherical AlN filler. However, the sintering process of the granulesintered-type AlN filler is time-consuming because AlN powder is a raw material and the granules of small AlN powder contain organic binder. Thereafter, the organic binder is burned and AlN granules are sintered; hence, this process is expensive. In addition, agglomerated particles are present owing to the influence of the binder. However, these particles are disadvantageous for resin filling, resulting in large surface roughness and poor conformability of the resin. In addition, small voids exist in the particles, which causes break down voltage reduction.

In this study, a large size AlN filler was synthesized via carbo-thermal reduction and nitridation $(\mathrm{CRN})$ of $\mathrm{Al}_{2} \mathrm{O}_{3}$. The CRN of $\mathrm{Al}_{2} \mathrm{O}_{3}$ to $\mathrm{AlN}$ involves the internal mixing of aluminum oxide with carbon, and it must take place at a 
high temperature in a flowing nitrogen atmosphere. The overall reaction during $\mathrm{CRN}$ is expressed as follows.

$$
\mathrm{Al}_{2} \mathrm{O}_{3}+3 \mathrm{C}+\mathrm{N}_{2} \rightarrow 2 \mathrm{AlN}+3 \mathrm{CO}
$$

We ensured that AlN of various particle sizes are separately produced in a short process. The difference of the AlN filler from the conventional one is its less agglomeration and independent particles. Further, the characteristics of the particles are less void and with smooth particle surfaces. These features impart high thermal insulation, high flow ability and high reliability to the resin composite.

The developed new AlN filler with large size was evaluated and the properties of the new AlN filler for the resin composite were discussed.

\section{Experimental Procedures}

\subsection{Sample preparation}

The new large size AlN filler was prepared using the CRM method. The conventional granule-sintered-type AIN filler was employed as a reference of the large size AlN filler.

JER828 (Mitsubishi Chemical Corp.) was the epoxy resin used. The AlN filler and resin were mixed in a mortar. Epoxy resin curing was performed at $100^{\circ} \mathrm{C}$ for $1 \mathrm{~h}$, and imidazole was used a as hardener of the epoxy resin.

KE-1013A/B (Shin-Etsu Chemical Co.) was used as silicone resin. The AlN filler and resin were mixed in a mortar, and silicone resin curing was performed at $120^{\circ} \mathrm{C}$ for 1 $\mathrm{h}$ (sample thickness of $2 \mathrm{~mm}$ ).

\subsection{Measurement}

The thermal conductivity of the resin composite filled with AlN filler for various filling rates were assessed using a laser flash method (Kyoto Denshi Corp.). The surface area was measured using a BET method, and the particle size distributions were evaluated using the laser diffraction method. Moreover, the spiral flow of the epoxy resin was measured by transfer molding in accordance with EIMS T9012006.

\section{Results and Disscution}

\subsection{Morphology and properties of the new large size AlN filler}

Large size AlN fillers, with nominal sizes of 5 and $25 \mu \mathrm{m}$, were experimentally produced through CRN. The particle size distribution was assessed using a laser diffraction particle size distribution apparatus (Fig. 1). The round shape, flat surface, and less agglomeration were observed via scanning electron microscopy (SEM) (Figs. 2 and 3). Based on the morphology, these fillers would be suitable for filling into resin composites.

The powder properties of the large size AlN filler were evaluated, as presented in Table 1. The specific surface area of the $25 \mu \mathrm{m}$ AlN filler was one tenth, and the tap density was three times of the $1 \mu \mathrm{m}$ AlN filler. Hence, the 25

Table 1 Properties of developed AlN fillers.

\begin{tabular}{c|c|c|c|c|c}
\hline \multicolumn{3}{c|}{ Type } & $1 \mu \mathrm{m}$ & $5 \mu \mathrm{m}$ & $25 \mu \mathrm{m}$ \\
\hline \multicolumn{2}{c|}{ S.A } & $\mathrm{m}^{2} / \mathrm{g}$ & 2.6 & 0.9 & 0.2 \\
\hline \multirow{3}{*}{$\begin{array}{c}\text { Particle } \\
\text { size }\end{array}$} & $\mathrm{D} 10$ & $\mu \mathrm{m}$ & 0.7 & 1.9 & 9.2 \\
\cline { 2 - 6 } & $\mathrm{D} 50$ & $\mu \mathrm{m}$ & 1.2 & 4.5 & 25 \\
\cline { 2 - 6 } & $\mathrm{D} 90$ & $\mu \mathrm{m}$ & 3.2 & 9.1 & 50 \\
\hline \multicolumn{2}{c}{ Tap density } & $\mathrm{g} / \mathrm{cm}^{3}$ & 0.5 & 1.0 & 1.6 \\
\hline
\end{tabular}

※.A.: specific surface area

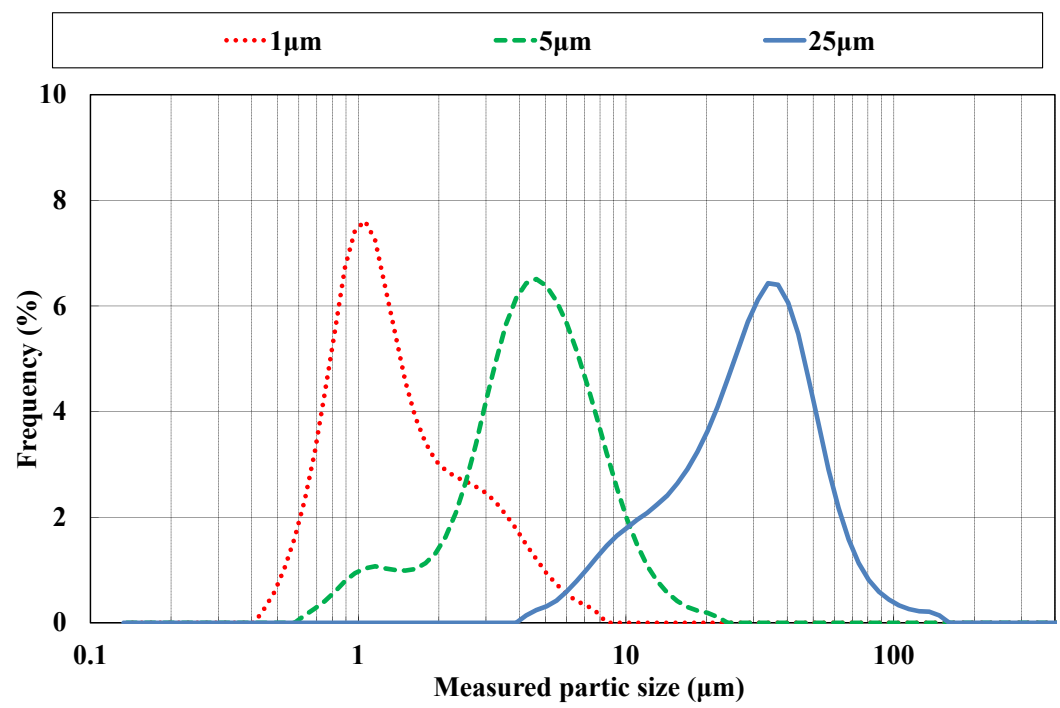

Fig. 1 Particle size distribution of the new AlN fillers. 


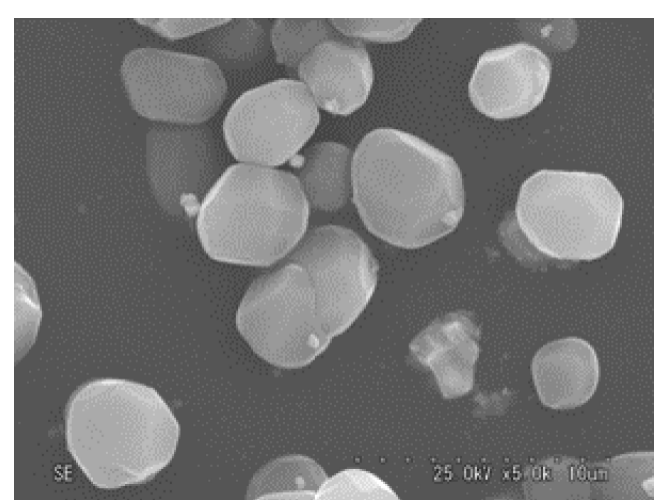

Fig. 2 SEM photograph of the large size AlN filler (D50: 5 $\mu \mathrm{m})$.

\section{Developed large size AIN filler}
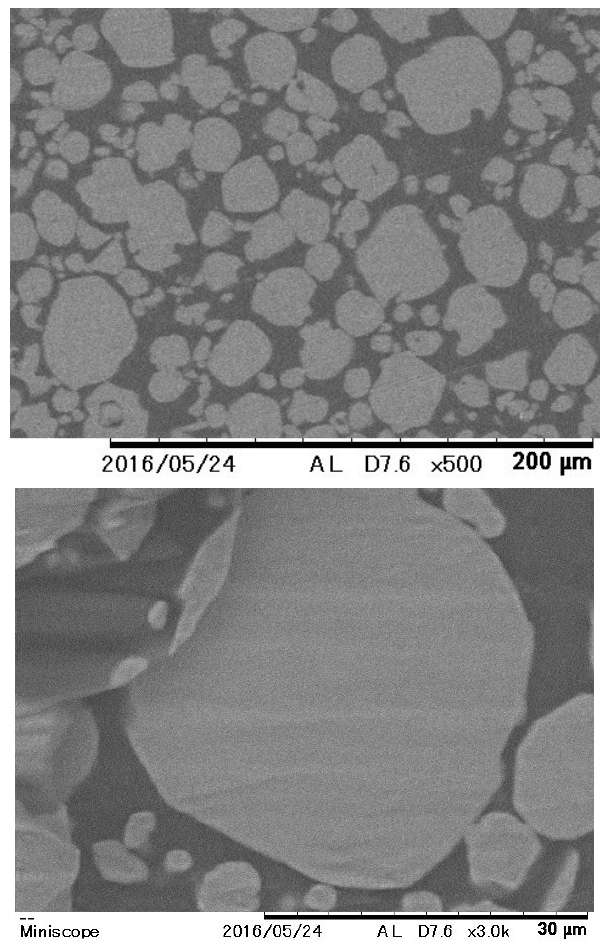

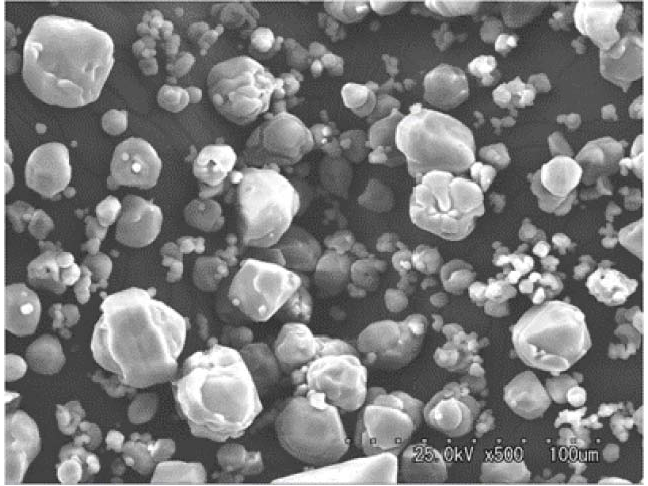

Fig. 3 SEM photograph of the large size AlN filler (D50: 25 $\mu \mathrm{m})$.

\section{Conventional large size AIN filler}
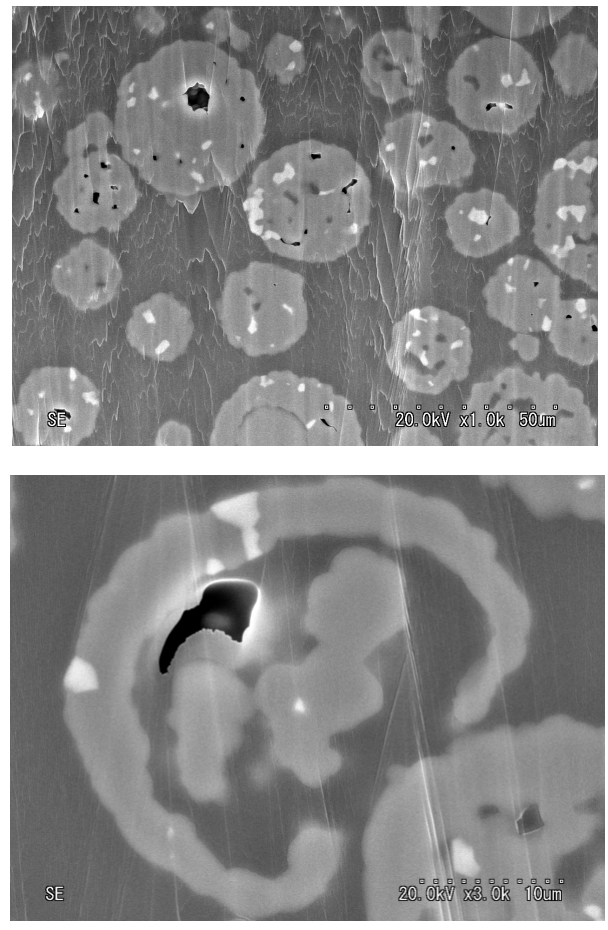

Fig. 4. Cross-section of the large size AlN filler.

$\mu \mathrm{m}$ AlN filler was assumed to have high flow ability in the resin and a high filling rate.

To confirm the densification inside the AlN filler, the cross section of the new large size AlN filler was observed via SEM, as shown in Fig. 4. Voids were not observed inside the AlN filler, but they were in the conventional AlN filler. Therefore, high insulation, low partial discharge, high breakdown voltage, high packing rate, and high thermal conductivity can be expected while using the large size AlN filler.

\subsection{Evaluations of the epoxy resin composite with} the large size AlN filler

As shown in Fig. 5, the thermal conductivity of the epoxy resin filled with trinomial distribution AlN filler was measured. The filling rate of up to 80 vol.\% was achieved. The relation between the filling rate and thermal conductivity almost matched Bruggeman's formula.[10] Meanwhile, the thermal conductivity of the epoxy resin containing AlN filler at 80 vol.\% reached $12 \mathrm{~W} / \mathrm{m} \mathrm{K}$. These results were perhaps due to the close packing structure of the AlN filler in the resin and the formation of preferred thermal passes. In addition, they presumably come from the filler morphology, the particle sizes, and the particle size distributions.

A spiral flow measurement of the epoxy filled with trinomial distribution AlN filler was facilitated using a transfer molding method based on EIMS (a test method for molding compound for semiconductor encapsulation). 


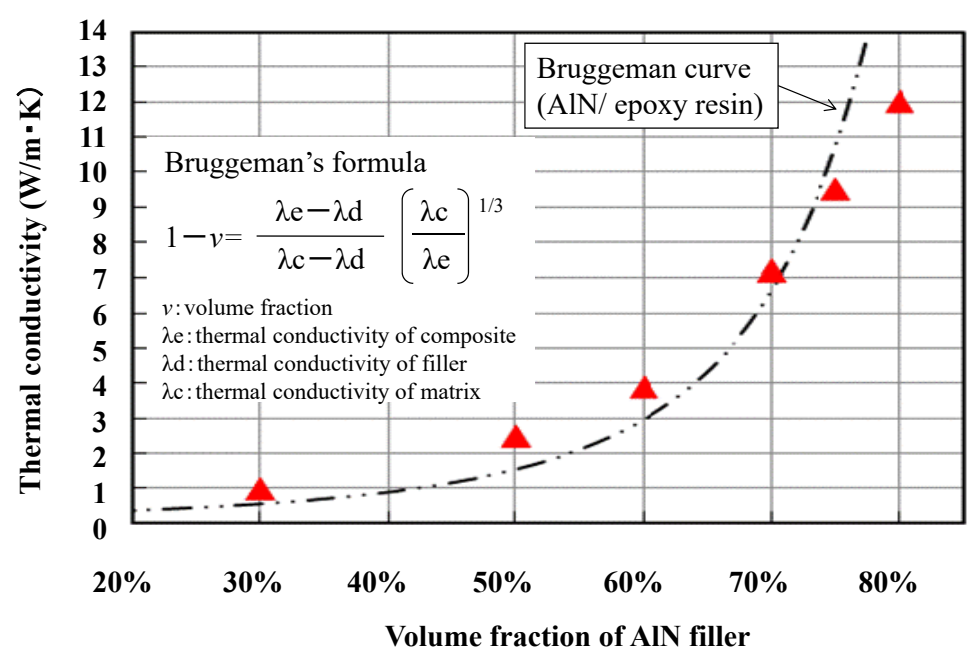

Fig. 5 Thermal conductivity of epoxy resin filled with AlN filler.

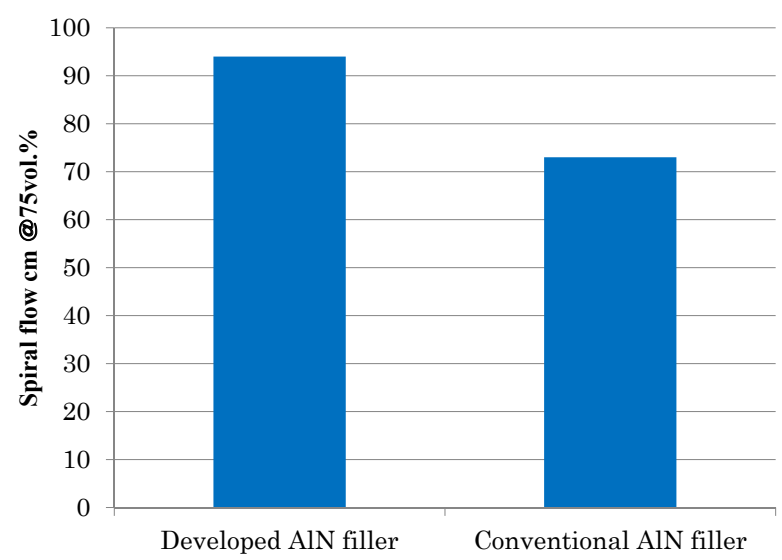

Fig. 6 Spiral flow of epoxy resin and large size AlN filler composite.

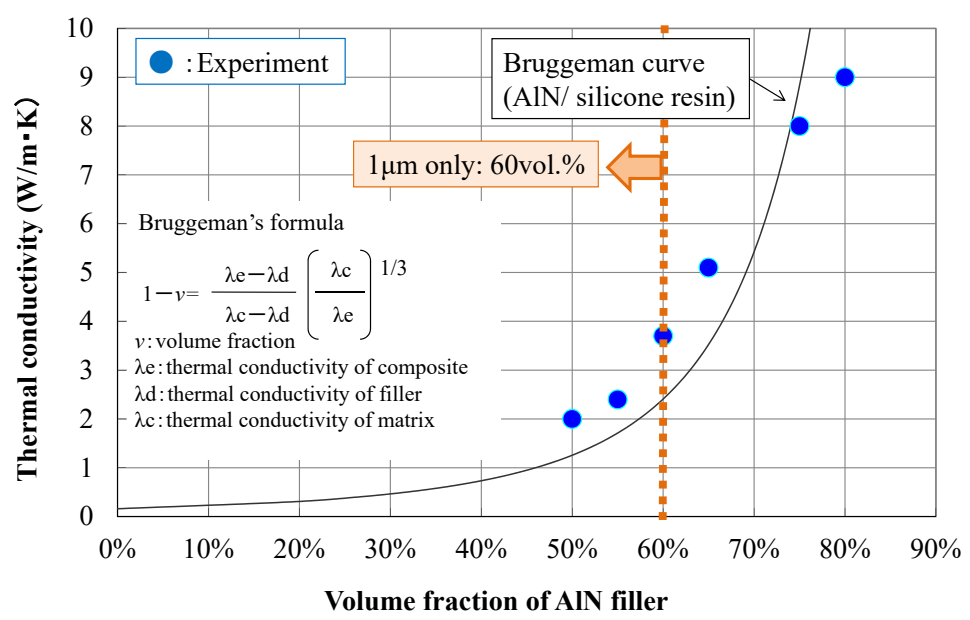

Fig. 7 Thermal conductivity of silicone resin filled with AlN filler.

Meanwhile, the measured temperature was $175^{\circ} \mathrm{C}$, and the flow width was $4 \mathrm{~mm}$. As shown in Fig. 6, the epoxy resin filled with the large size AlN filler achieved approximately 1.3 times longer spiral flow as compared to conventional large size AlN filler at 75 vol.\%. The new AlN filler was confirmed to provide more fluidity to the resin in comparison with the conventional AlN filler. The new AlN filler has a smooth surface. Therefore, it has good kneadability with resin. 


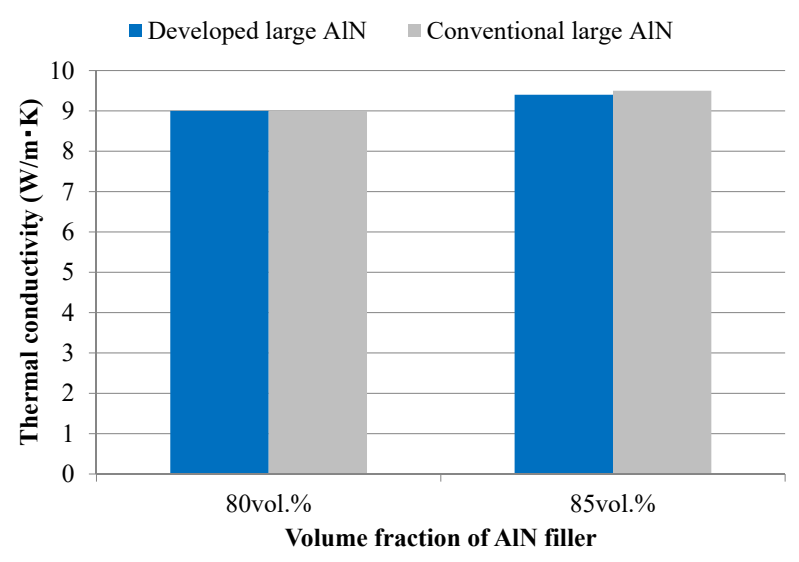

Fig. 8 Thermal conductivity of silicone resin filled with large AlN filler.

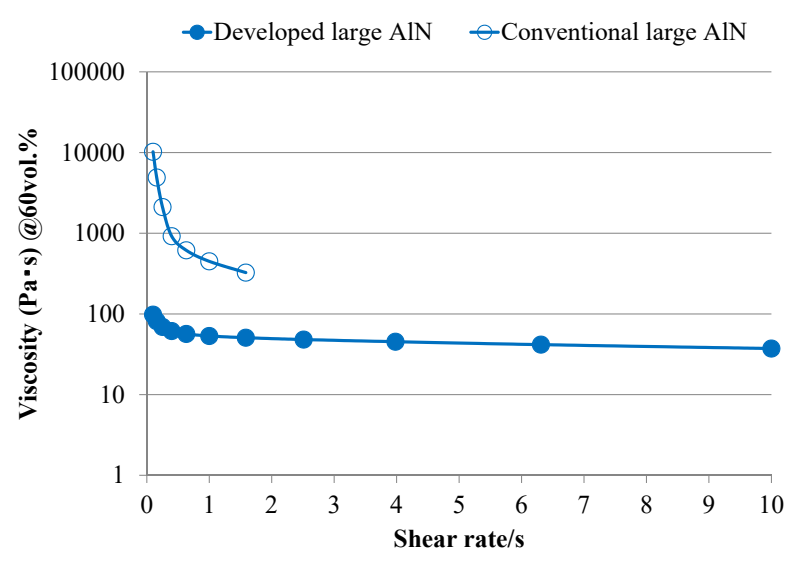

Fig. 9 Viscosity of silicone resin filled with large AlN filler.

\subsection{Evaluations of the silicone resin composite with the large size AlN filler}

Figure 7 shows the thermal conductivity of the silicone resin filled with the AlN filler. In the case of silicone resin, the trinomial particle size distribution is effective in obtaining high filling rate. The filler was filled to approximately $80 \mathrm{vol} . \%$. If AlN is $1 \mu \mathrm{m}$, the filler rate was only 60 vol.\%. This particle size distribution is also effective to high packing. High filling increases the contact points, and it also enables high thermal conductivity.

The thermal conductivity of the AlN/silicone composite was $9 \mathrm{~W} / \mathrm{mK}$, whereas that of developed large AlN filler was almost the same as the conventional large AlN filler with 85 vol.\% content (Fig. 8).

Viscosity of silicone resin filled with $25 \mu \mathrm{m}$ AlN filler is shown in Fig. 9. Silicone resin filled with the $25 \mu \mathrm{m}$ AlN fillers had one tenth lower viscosity compared to conventional at 60 vol\%. Developed $25 \mu \mathrm{m}$ AlN filler has smoother particle surface than conventional AlN filler. Therefore, its conformability with the resin is assumed to be excellent, indicating good handle ability, high filling rate, and high

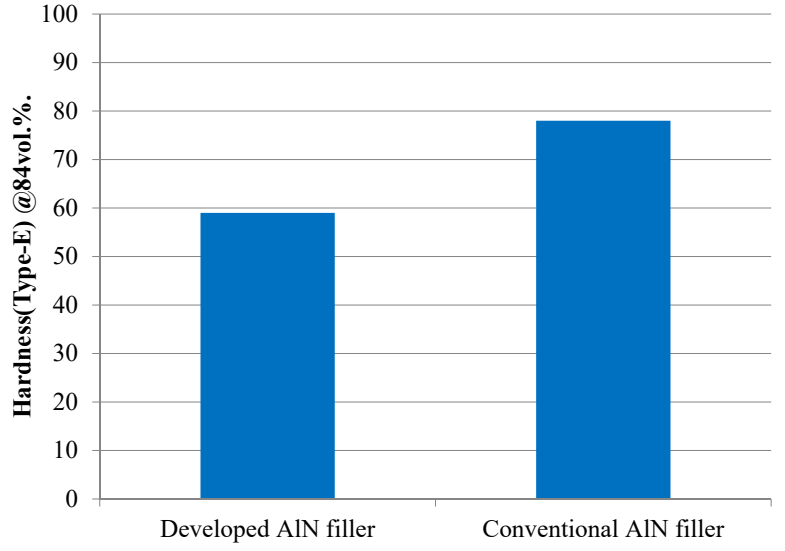

Fig. 10 Type E hardness of silicone resin and large size AlN filler composite.

resin flexibility.

A type E durometer was used to measure the hardness of the silicone resin filled with large AlN filler. The filling rate was up to $84 \mathrm{vol} . \%$. Also, the AlN filler ratio of $25 \mu \mathrm{m}$ and $1 \mu \mathrm{m}$ was 7:3. As shown in Fig. 10, the hardness of silicone resin filled with the large AlN filler was $20 \%$ lower than the conventional filler. Therefor, Flexibility and adhesion will be increased, which is good influence to low heat thermal resistance.

\section{Conclusion}

New AlN fillers with large size and spherical shape, with average diameters from 5 to $25 \mu \mathrm{m}$ were developed using the CRN method. These fillers were suitable to be high thermal conductivity filler for resin composites. In this research, the high thermal conductivity of the epoxy resin was obtained using the novel large size AlN filler. Moreover, the fluidity of the AlN-filled epoxy resin was enhanced with the optimal blending ratio of the novel AlN filler. The hardness of the silicone resin also improved the flexibility and adhesion of the filler, possibly resulting in its low thermal resistance.

\section{References}

[1] W. T. Minehan, D. S. Horn, W. K. Weidner, and J. E. Volmering, "Current Technology for Hot Pressed, Co-fired AlN Electronic Packages," Advancing Microelectronics, Jan/Feb. pp. 31-33, 1994.

[2] R. Hahn, V. Glaw, A. Ginolas, M. Topfer, K. Wittke, and H. Reichi, "High performance liquid cooled aluminum nitride heat sinks," Microelectronics International, 16/1, pp. 21-26, 1999.

[3] Y. Nagai and Gao-Chao Lai, "Thermal Conductivity of Epoxy Resin Filled Particulate Aluminum Nitride 
Powder,” J. Ceram. Soc. Japan, Vol. 105, No. 3, pp. 197-200, 1997.

[4] E.-S. Lee and S.-M. Lee, "Enhanced Thermal Conductivity Polymer Matrix Composite via High Solids Loading of Aluminum Nitride in Epoxy Resin,” J. Am. Ceram. Soc., Vol. 91, No. 4, pp. 1169-1174, 2008.

[5] S. K. Lee, H. Horibe, I. Yamada, S. Kume, K. Watari, and K. Mitsuishi, "Polymer Composites with Ceramics Fillers for Thermal Conductivity,” J. Soc. Inorg. Mate, Japan, Vol. 14, pp. 429-436, 2007.

[6] H. Tezuka, "Development of insulated/thermal conductivity sheet used AlN filler," FC report, Vol. 29, No. 3, pp. 100-102, 2011.

[7] Y. Takao and M. Sando, "Flame Synthesis of Aluminum Nitride Filler-Powder,” J. Chem. Eng. Japan, Vol. 34, No. 6, pp. 828-833, 2001.

[8] T. Suehiro, J. Tatami, T. Meguro, S. Matsuo, and K. Komeya, "Synthesis of spherical AlN particles by gas-reduction-niridation method,” J. Euro. Ceram. Soc., Vol. 22, pp. 521-526, 2002.

[9] M. Ohashi, S. Kawakami, and Y. Yokogawa, "Spherical Aluminum Niride Fillers for Heat-Conducting Plastic Packages,” J. Am. Ceram. Soc., Vol. 88, No. 9, pp. 2615-2618, 2005.

[10] D. A. G. Bruggeman, Ann. Phys., Vol. 24, 636-664, 1935.
Akimasa Kuramoto
Yutaka Fukunaga
Yasushi Imoto
Yoshitaka Inaki
Saiko Fujii
Meng Wang
Yukihiro Kanechika
Teruhiko Nawata
Masahide Ueda 